\title{
EXPLORAÇÃO FLORESTAL SEMIMECANIZADA E AS IMPLICAÇÕES NA SAÚDE E NA SEGURANÇA DO TRABALHADOR
}

\author{
LEAL, Fabrício Assis ${ }^{1}$ \\ CARVALHO, Carlos Eduardo ${ }^{2}$
}

Recebido em: 2011-04-18

Aprovado em: 2011-10-27

ISSUE DOI: $10.3738 / 1982.2278 .588$

\begin{abstract}
RESUMO: O Índice de Bulbo Úmido - Termômetro de Globo, IBUTG, tem papel importante no planejamento das atividades que acontecem sobre a presença de carga térmica. A legislação prevê, com base no IBUTG,duas situações para trabalho intermitente,com descanso no próprio local e em outro local.O objetivo deste trabalho foi avaliar a exploração florestal comparando a produtividade de madeira cortada entre dois grupos de trabalhadores, com e sem descanso. A área em estudo está localizada às margens da rodovia BR 060, na altura do km 397, em Rio Verde/Goiás. O talhão avaliado foi plantado com Eucalyptus urophylla S. T. Blake, em 24,98 hectares. O índice foi calculado conforme a fórmula para ambientes externos com carga solar. Para comparar resultados foi monitorado durante todo o dia a produção em volume de madeira cortada (st), obedecendo cinco horários pré-estabelecidos (09:00, 11:00, 14:00, 16:00 e 18:00 h).Realizou-se um delineamento em blocos casualizados (DBC), em esquema fatorial $2 \times 5$, e teste $\mathrm{T}$ ao nível de $99 \%$ de probabilidade. O IBUTG médio encontrado foi de 25,8 e o regime adotado foi de 45 minutos de trabalho e 15 minutos de descanso. Não houve diferenças significativas, ao nível de $1 \%$ de probabilidade, entre a variável analisada para os grupos com e sem descanso. Porém houve diferença significativa para os Horários avaliados. Fica evidenciado que independentemente do IBUTG calculado, o descanso poderia ser oferecido pela empresa sem nenhum ônus aos funcionários, uma vez que estatisticamente não houve diferença significativa entre os regimes de trabalho adotados.
\end{abstract}

Palavras-chave: IBUTG. NR-15. Exploração florestal.

\section{FOREST EXPLORATION SEMI MECHANIZEDANDTHEIMPLICATIONSIN HEALTHANDSAFETYOF WORKERS}

\begin{abstract}
SUMMARY: The Wet Bulb Index - Globe Thermometer, IBUTG, has an important role in planning the activities that happen on the presence of heat load. The legislation provides, based on the IBUTG, two situations to work intermittently, with rest on the spot and elsewhere. The aim of this study was to evaluate the forestry comparing the productivity of timber harvested between two groups of workers with and without rest. The study area is located beside the highway BR 060, at km 397, Rio Verde/Goiás. The measured plot was planted with Eucalyptus urophylla S. T. Blake, with 24.98 hectares. The index was calculated using the formula for outdoors with solar load. Was monitored throughout the day in the production volume of wood cut (st), according to five times pre-established (09:00, 11:00, 14:00, 16:00 and 18:00). This was a randomized block design (DBC) in a factorial $2 \times 5$, and T test at $1 \%$ significance. The average IBUTG was found to be 25.8 and the system adopted was 45 minutes work and 15 minutes of rest. There were no significant differences at the $99 \%$ level of probability between the variable analyzed for the groups with and without rest. However, there was significant difference for the times evaluated. It is evident that regardless of IBUTG calculated, the rest could be offered by the company at no cost to employees, since no statistically significant difference between the schemes of work adopted.
\end{abstract}

Keywords: IBUTG, NR-15, Forest exploration.

\footnotetext{
${ }^{1}$ Eng. ${ }^{\circ}$ Florestal, pós-graduando em Eng. ${ }^{a}$ de Segurança do Trabalho. E-mail: fabricioassisleal@ yahoo.com.br.

${ }^{2}$ Orientador, Eng. ${ }^{\circ}$ de Segurança do Trabalho e Eng..$^{\circ}$ Mecânico. E-mail: c-eduardo-carvalho@ uol.com.br.
} 


\section{INTRODUÇÃO}

Antes da década de 60,o setor florestal contribuía com pouca expressividade para a atividade econômica brasileira. Porém, a partir desta, o segmento teve uma ascendência significativa, ganhando forças principalmente após a criação de incentivos fiscais, para a implantação de florestas de rápido crescimento, diminuindo a exploração dos recursos florestais naturais (NOVAIS, 2006).

As atividades de exploração em plantios florestais com fins energéticos, em empresas e propriedades rurais, são, na maioria das vezes, terceirizadas para empresas de pequeno, médio e grande porte, que oferecem os equipamentos e as pessoas treinadas para a realização completa da exploração florestal.

A terceirização no setor florestal, principalmente no corte de florestas plantadas, pode, em alguns casos, abreviar e muito o tempo de exploração de uma determinada área. Porém, muitas empresas terceirizadas não fornecem todos os equipamentos necessários aos seus colaboradores da forma como deveria ser.

Segundo Bracelpa (2008), em 2007, aproximadamente $85 \%$ da mão-de-obra empregada na atividade florestal realizada pelas indústrias do setor de papel e celulose era oriunda de empresas terceirizadas.

Um cenário bastante significativo sobre a terceirização no setor florestal foi constatado por Leite, Souza e Machado (2002) apud Souza e Pires (2009), onde identificaram, em algumas empresas brasileiras de reflorestamento, que a adoção da estratégia de terceirização na colheita florestal situava-se em torno de $63 \%$ na extração, $69 \%$ no carregamento, $100 \%$ no transporte e de $56 \%$ no descarregamento. Apoiando-se numa média de terceirização bastante expressiva de $71 \%$.

Grande parte dos povoamentos florestais explorados no Brasil faz-se com o uso do motosserra. Equipamento esse indispensável para o formato de exploração em pequenas e médias escalas, mas com sérios problemas para a saúde e segurança do trabalhador.

Não bastassem as dificuldades e os riscos que a exploração florestal semimecanizada naturalmente oferecem aos trabalhadores desse segmento, o meio ambiente de trabalho também tem uma parcela importante e não menos significativa nesse contexto.

Dentre os principais fatores físicos indesejados na exploração florestal, podemos destacar o calor. O calor é uma forma de energia que se transfere de um sistema para outro em virtude de uma diferença de temperatura entre os mesmos, somando negativamente para a saúde e a segurança do trabalhador, principalmente, em atividades de exploração florestal. 
O IBUTG é um índice que tem valor legal, estabelecido pelo Anexo3 da Norma Regulamentadora (NR) $\mathrm{n}^{\mathrm{o}}$ 15, da portaria 3.214/78 do Ministério do Trabalho. O IBUTG leva ainda em consideração o tipo de atividade desenvolvida (leve, moderada e pesada), e que pode ser avaliada por classe ou por tarefa, quantificando a tarefa em $\mathrm{kcal} / \mathrm{h}$.

A legislação prevê duas situações com base no IBUTG, um regime de trabalho em função do valor desse índice e do tipo de atividade: (1) Regime de trabalho intermitente com períodos de descanso no próprio local; (2) Regime de trabalho intermitente com descanso em outro local.

O objetivo deste trabalho foi avaliar a exploração florestal semimecanizada em um plantio de Eucalyptus urophyllaS. T. Blake, no sudoeste goiano, verificando e comparando a produtividade de madeira cortada entre dois grupos de trabalhadores, o primeiro seguindo o Anexo 3 da NR-15 (com descanso) e o outro seguindo o regime de trabalho atribuído pela empresa terceirizada (sem descanso).

\section{MATERIAL E MÉTODOS}

A área em estudo está localizada às margens da rodovia BR 060, na altura do km 397, zona rural, no município de Rio Verde em Goiás, com altitude média de 780 metros, entre as coordenadas geográficas $-17^{\circ} 51^{\prime} 04^{\prime}$ ' e $-17^{\circ} 51^{\prime} 36^{\prime}$ ' de latitude S e $-51^{\circ} 03$ ' $15^{\prime}$ ' e $-51^{\circ} 04^{\prime}$ 04', de longitude W.

O receptor GPS utilizado para o levantamento dos limites do talhão e para a marcação dos pontos de monitoramento do IBUTG foi o GPSMAP 60CSx da Garmin, e os pontos marcados tiveram configuração de saída em coordenadas sexagesimais, ou seja, grau, minuto e segundo, e o Datum adotado foi o South American Datum - SAD 69.

Para os cálculos da área (hectare) do talhão em estudo e a confecção dos layouts georreferenciados, aqui apresentados, foi utilizado o software ArcGIS. A base cartográfica, utilizada nos layouts, foi disponibilizada pelo Instituto Brasileiro de Geografia e Estatística IBGE, em formato vetorial, Malha Municipal Digital do Brasil-2007, escala 1:500.00.

A Malha Municipal Digital do Brasil é um produto cartográfico do IBGE, elaborado pela Coordenação de Cartografia, a partir do Arquivo Gráfico Municipal - AGM, composto pelas folhas topográficas na melhor escala disponível nas diversas regiões do país. A FIGURA 1 mostra a localização do município, bem como a espacialização da área em estudo em Rio Verde, Estado de Goiás. 
Figura 1: Localização do município de Rio Verde, limites dos municípios confrontantes e a espacialização da área em estudo no município.

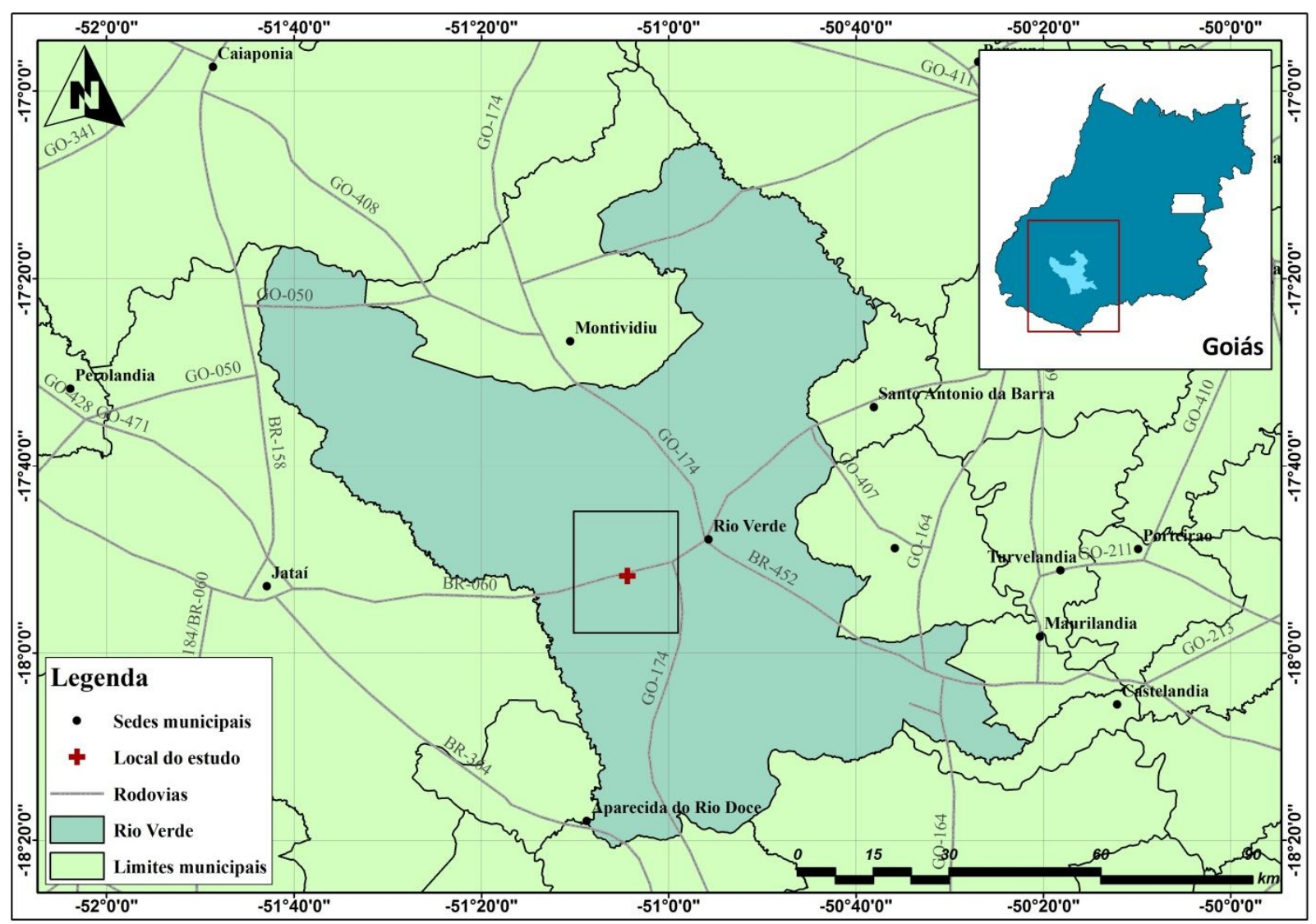

Fonte: Leal e Carvalho (2011).

O talhão avaliado no presente trabalho foi plantado em julho 2003, com a espécie Eucalyptus urophylla S. T. Blake, em espaçamento $3 \times 2$ metros, tendo como área 24,98 hectares, somando,no total,aproximadamente 41.640 árvores(1.667 árvores/ha). Valor esseconsiderando falhas, indivíduos em senescência e mortos.

Para a obtenção do IBUTG (índice de bulbo úmido - termômetro de globo) foi utilizado um termômetro de globo digital TGD 200 (Instrutherm), com escala de $-10^{\circ} \mathrm{C}$ a $150^{\circ} \mathrm{C}$, de precisão de $\pm 0,1^{\circ} \mathrm{C}$.

Para o monitoramento das equipes em campo foram amostrados dois pontos para medição das temperaturas. Sendo que em cada um dos pontos, o aparelho ficou trinta minutos (30) estabilizando para posteriormente serem efetuadas as leituras dos termômetros.

Esse procedimento também foi realizado dois dias antes da exploração monitorada, nos horários pré-estabelecidos para mensuração do volume cortado de madeira. $\mathrm{O}$ intuito foi conhecer um índice médio que antecedia as atividades e também para nortear as ações no dia do monitoramento propriamente dito. 
O primeiro ponto de medição de temperatura tem coordenadas geográficas de $-17^{\circ} 51^{\prime}$ 20' em Latitude S e de $-51^{\circ} 03$ ' 38', em longitude W. O segundo ponto de medição de temperatura tem coordenadas geográficas de $-17^{\circ} 51^{\prime} 29^{\prime}$ ' em latitude $\mathrm{S}$ e de $-51^{\circ} 03^{\prime} 31^{\prime}$ ' em longitude W. A FIGURA 2 mostra o mapa do talhão que serviu para avaliaçãodo estudo, bem como a espacialização dos dois pontos de monitoramento, das temperaturas, no talhão.

Figura 2: Talhão de Eucalyptus urophylla S. T. Blake, avaliado na exploração florestal semimecanizada e os dois pontos de monitoramento das temperaturas (IBUTG).

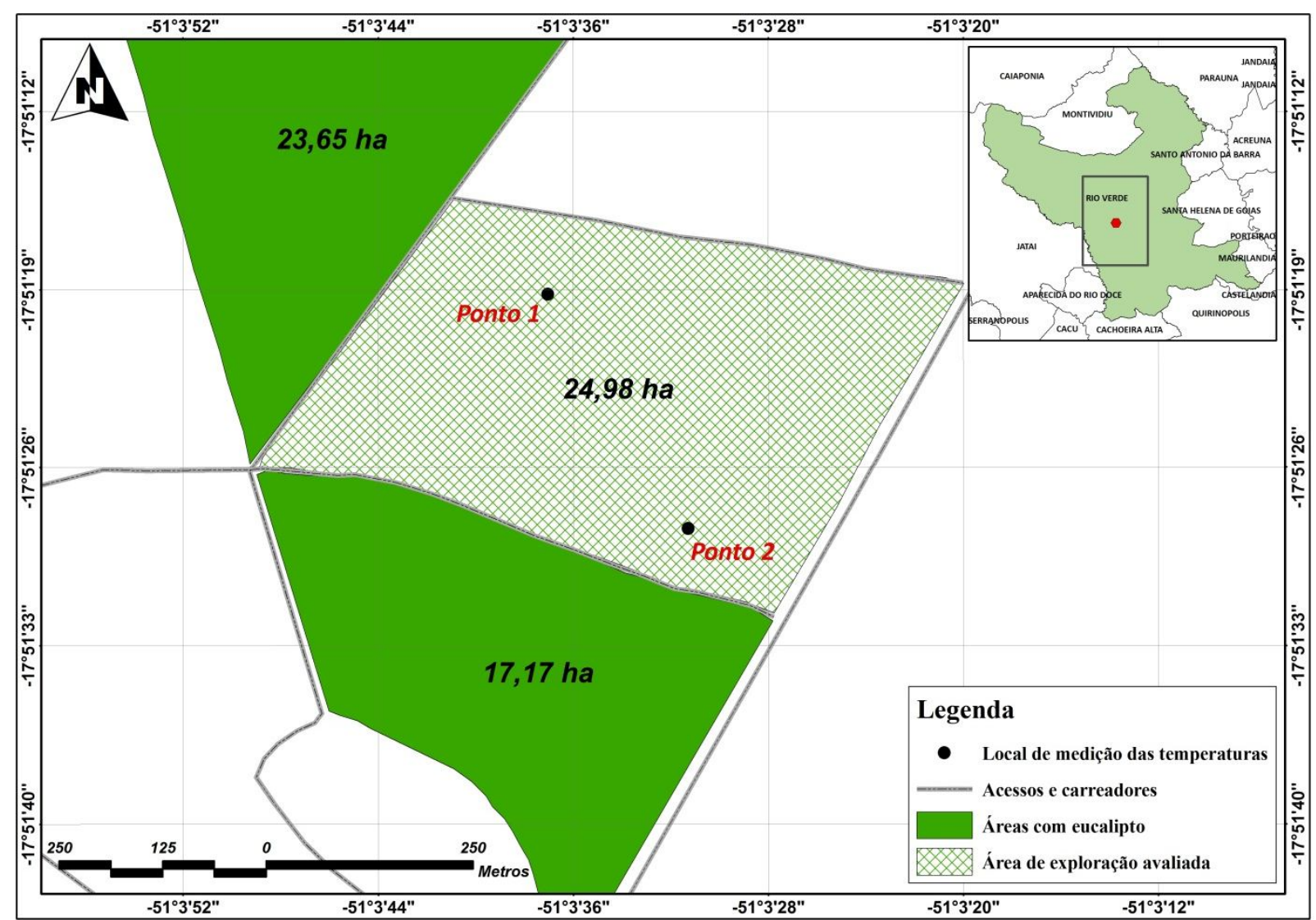

Fonte: Leal e Carvalho (2011).

O IBUTG foi calculado a partir de três medições, sendo: (1) Termômetro de Bulbo Seco (Tbs): é um termômetro comum, cujo bulbo fica em contato com o ar. Portanto, foi obtido dele a temperatura do ar; (2) Termômetro de Bulbo Úmido Natural (Tbn): é um termômetro cujo bulbo é recoberto por um pavio hidrófilo, o qual sua extremidade foi imersa em água destilada, deixando $25 \mathrm{~mm}$ de pavio livre de qualquer obstáculo, a partir do início da parte sensível do termômetro; e (3) Termômetro de Globo (Tg): é um aparato que possui um termômetro (ousensor equivalente) posicionado no centro de uma esfera oca de cobre, comdiâmetro de seis polegadas $(15,24 \mathrm{~cm})$. A esfera foi preenchida naturalmente com ar e a abertura foi fechada pela rolha do termômetro. 
Após a obtenção das medições, citadas anteriormente, foi aplicado à fórmula preconizada para ambientes externos com carga solar, conforme NR-15. E posterior a isso foi obtido o IBUTG para dimensionar o grupo conforme o regime de trabalho. A fórmula recomendada e utilizada foi a seguinte: $\mathrm{IBUTG}=0,7 \mathrm{Tbn}+0,1 \mathrm{Tbs}+0,2 \mathrm{Tg}$.

Como o descanso ofertado não seria no mesmo local de trabalho, e sim em abrigos instalados pelas próprias equipes contra intempéries, em concordância com a NR-21, foi realizada a mediação das temperaturas nesses abrigos, onde o objetivo seria obter o IBUTG para posteriormente calcular os limites de tolerância para exposição ao calor, em regime de trabalho intermitente com período de descanso em outro local.

Como pré-requisito para o cálculo dos limites de tolerância para exposição ao calor, foi obtida a taxa de metabolismo média ponderada para uma hora, determinada pela seguinte fórmula:

$$
\mathbf{M}=\left[\frac{\left(\mathbf{M}_{\mathrm{t}} \times \mathbf{T}_{\mathrm{t}}\right)+\left(\mathbf{M}_{\mathrm{d}} \times \mathbf{T}_{\mathrm{d}}\right)}{60}\right]
$$

Sendo que: $\mathrm{M}_{\mathrm{t}}=$ taxa de metabolismo no local de trabalho; $\mathrm{T}_{\mathrm{t}}=$ soma dos tempos, em minutos, em que se permanece no local de trabalho; $\mathrm{M}_{\mathrm{d}}=$ taxa de metabolismo no local de descanso; $\mathrm{T}_{\mathrm{d}}=$ soma dos tempos, em minutos, em que se permanece no local de descanso.

Para saber se o IBUTG encontrado nos locais de descanso estava dentro do valor máximo permitido, segundo o metabolismo médio ponderado, foi calculado o IBUTG médio ponderado para uma hora, determinado pela seguinte fórmula:

$$
\overline{\text { IBUTG }}=\left[\frac{\left(\text { IBUTG }_{\mathrm{t}} \times \mathrm{T}_{\mathrm{t}}\right)+\left(\text { (BUTG }_{\mathrm{d}} \times \mathrm{T}_{\mathrm{d}}\right)}{60}\right]
$$

Sendo que: IBUTG $_{t}=$ valor do IBUTG no local de trabalho; IBUTG $_{\mathrm{d}}=$ valor do IBUTG no local de descanso, $\mathrm{T}_{\mathrm{t}}$ e $\mathrm{T}_{\mathrm{d}}=$ como anteriormente definidos.

A exploração iniciou-se em setembro de 2010, portanto o corte foi realizado sete anos e dois meses após o plantio. A supressão aconteceu em período integral com dois grupos de trabalhadores definidos. Cada grupo era composto por três duplas, e cada dupla continha um operador de motosserra e um ajudante. O modelo do motosserra utilizado foi o 041 da Stihl, cujo peso sem o conjunto de corte é de $6,8 \mathrm{~kg}$ e potência de 4 HP (Horse-power).

A supressão era feita com o motosserra, onde o operador iniciava o corte olhando a direção natural de queda da árvore, posteriormente o mesmo fazia um entalhe direcional e 
consequentemente o corte de abate. $\mathrm{O}$ ajudante auxiliava-o com um equipamento chamado de fisga, que consistia num cabo longo de madeira leve de comprimento aproximado de dois metros e meio ( $2,5 \mathrm{~m}$ ), acoplado a um terminal de ferro do tipo garfo (fisga). Esse equipamento auxiliava na queda da árvore e, em algumas situações, podia até tendenciar a queda em árvores com diâmetros menores.

Os grupos foram separados, com e sem descanso, para a avaliação. O descanso oferecido foi aquele advindo do IBUTG após os cálculos e os critérios preconizados no Anexo 3 da NR-15.

A escolha dos grupos acorreu de forma aleatória através de um sorteio. Assim sendo, foi eliminado qualquer julgamento pessoal na escolha das equipes, bem como mitigada qualquer tendência que por ventura viesse a acontecer no direcionamento das mesmas.

Para a comparação entre os grupos estudados foi monitorado durante todo o dia, a produção em volume de madeira cortada, obedecendo cinco horários pré-estabelecidos para todos os grupos. Como a chegada das equipes em campo era sempre as 06h45min. da manhã, e o inicio dos trabalhos em campo começava as 07:00 h, as mensurações dos volumes cortados foram realizadas de duas em duas horas, até o horário de saída, que é as 18:00 h.Foi desconsiderado na avaliação o intervalo de almoço dos colaboradores, sendo de 11:00 h as 12:00 h.

Deste modo, as medições foram realizadas nos seguintes horários: 09:00 h (contempla a produtividade entre 07:00 e 09:00 h), 11:00 h (contempla a produtividade entre 09:00 e 11:00 h), 14:00 h (contempla a produtividade entre 12:00 e 14:00 h), 16:00 h(contempla a produtividade entre 14:00 e 16:00 h) e 18:00 h(contempla a produtividade entre 16:00 e 18:00 h).

Em cada horário de medição, os grupos eram visitados simultaneamente e o material lenhoso cortado era mensurado com fita métrica, de graduação em milímetros. A unidade de volume adotada foi o estéreo (st), pela padronização da unidade de volume seguida pela empresa terceirizada.

Ao todo foram seis equipes avaliadas, sendo que três equipes trabalharam sem descanso, seguindo o ritmo proposto pela empresa terceirizada, apenas parando no horário do almoço, de 11:00 as 12:00 h. E as outras três equipes trabalharam com descanso,adotando orientação da NR-15, em relação aos critérios do IBUTG já mencionados.

Nada fora esclarecido as equipes que participaram do trabalho, para que não houvesse interferências pessoais e propositais no dia do monitoramento e no rendimento do trabalho. Apenas foi elucidado que tal acompanhamento serviria para dimensionar melhor as equipes 
em campo em relação ao volume de material lenhoso cortado e a demanda da empresa. Vale ressaltar também que a empresa, ora visitada, trabalha e paga sobre o regime de produtividade, ou seja, os trabalhadores recebem mais quando produzem mais.

Para ver se houve diferença nos volumes de madeira cortadas (st) entre os grupos avaliados no regime de trabalho, com e sem descanso, com três repetições cada regime, foi feito um delineamento em blocos casualizados (DBC), em esquema fatorial 2 x 5, e teste $\mathrm{T}$ ao nível de $99 \%$ de probabilidade, usando o sistema de análises de variância para dados balanceados - SISVAR, (FERREIRA, 2000), em que a variável resposta utilizada foi o volume de madeira cortada (st).

O primeiro fator representa os grupos, com e sem descanso, e o segundo fator representa os horários em que foram efetuadas as medições do material lenhoso suprimido, 09:00, 11:00, 14:00, 16:00 e 18:00 horas, sendo duas horas de intervalo entre cada averiguaçãoin loco.

No propósito de elucidar as comparações entre os regimes de trabalho, com e sem descanso, em relação ao volume cortado nos horários determinados para as medições do volume, foi realizado um desdobramento do fator grupo (com e sem descanso) dentro de cada nível de horário (09:00, 11:00, 14:00, 16:00 e 18:00 horas),e, posteriormente, aplicado um teste T ao nível de $1 \%$ de significância.

Para entender o rendimento e a produtividade das equipes avaliadas foi desdobrado o fator horários (09:00, 11:00, 14:00, 16:00 e 18:00 horas) dentro de cada nível de grupo (com e sem descanso). O intuito foi descobrir se os volumes cortados nos horários pré-estabelecidos seriam constantes, crescentes ou decrescentes, haja vista que ao se aproximar do horário de saída dos colaboradores, os mesmos poderiam estar mais cansados e, pelo volume de madeira cortada presenciado em campo, não mantinham o mesmo rendimento.

\section{RESULTADO E DISCUSSÃO}

Após a avaliação nos dois pontos que serviram de monitoramento das temperaturas, foi possível notar que o IBUTG variou pouco entre os dias monitorados,e não houve alternância entre a faixa de 25,1 a 25,9, preconizando um regime de trabalho de 45 minutos com 15 minutos de descanso (Quadro 1, Anexo 3 da NR-15), para uma atividade pesada, onde se enquadra a exploração florestal semimecanizada. 
Os índices encontrados variaram durante o dia todo, principalmente nos horários após o almoço, 14:00 h e as 16:00 horas, ultrapassando inclusive o intervalo do IBUTG adotado para dimensionar as equipes em campo. Porém, como isso já estava previsto, foi adotada uma média dos índices encontrados durante o dia, para padronizar o regime de trabalho. O IBUTG do primeiro ponto de monitoramento foi de 25,8 e o IBUTG do segundo ponto foi de 25,7, confirmando então o regime de trabalho de 45 minutos e 15 minutos de descanso para o Grupo Com Descanso.

A Tabela 1 a seguir apresenta os resultados encontrados para o IBUTG, para os dois pontos de monitoramento nos dois dias que antecederam a atividade de exploração, bem como para o dia de avaliação propriamente dita e na área de descanso.

Tabela 1: IBUTG para os dias que antecederam a avaliação, bem como para o dia da avaliação nos dois pontos de monitoramento das temperaturas e na área de descanso.

\begin{tabular}{cccccc}
\hline \multirow{2}{*}{ Horário } & \multicolumn{2}{c}{ Monitoramento } & \multicolumn{2}{c}{ Dia da avaliação } & Local de \\
& $1^{\circ}$ dia & $2^{\circ}$ dia & $1^{\circ}$ ponto & $2^{\circ}$ ponto & descanso \\
\hline $09: 00$ & 22,6 & 22,7 & 22,9 & 23,5 & 21,1 \\
$11: 00$ & 25,3 & 27,1 & 26,2 & 25,2 & 21,4 \\
$14: 00$ & 27,3 & 27,4 & 27,5 & 27,3 & 23,4 \\
$16: 00$ & 28,1 & 27,4 & 27,5 & 27,5 & 23,6 \\
$18: 00$ & 24,2 & 24,7 & 25,1 & 24,9 & 21,3 \\
\hline Média IBUTG & $\mathbf{2 5 , 5}$ & $\mathbf{2 5 , 9}$ & $\mathbf{2 5 , 8}$ & $\mathbf{2 5 , 7}$ & $\mathbf{2 2 , 2}$ \\
\hline
\end{tabular}

Fonte: Leal e Carvalho (2011).

Com os resultados encontrados para o IBUTG foi possível dimensionar o Grupo Com Descanso, de forma que os seus componentes descansassem15 minutos, em outro local, ou seja, na mesma área e não no mesmo ponto de trabalho, em abrigos contra intempéries como citado na NR-21 sobre trabalhos a céu aberto. Assim sendo, estariam os mesmos expostos em outras condições ambientais e temperaturas mais amenas.

No Gráfico 1, a seguir, é apresentada também a linha média do valor IBUTG encontrada no estudo (25,8), durante a jornada de trabalho no dia do monitoramento. Confrontando os volumes médios cortados de madeira (st), com o horário em que o índice ultrapassou a média do IBUTG (25,8), é possível verificar que o decréscimo de rendimento ocorreu logo após o intervalo de almoço das equipes (Gráfico 2).

Apesar desses valores variáveis do IBUTG acometerem igualmente ambos os regimes de trabalho, com e sem descanso, no grupo que trabalhou descansando 15 minutos sistematicamente a cada 45 minutos trabalhados, as equipes tiveram reflexos positivos em relação a um trabalho mais cadenciado e aparentemente mais seguro. 
O Gráfico 1 a seguir mostra a variação do Índice de Bulbo Úmido - Termômetro de Globo (IBUTG) médio, ao longo da jornada de trabalho na exploração florestal, no dia do monitoramento e nos dois dias que antecederam o mesmo.

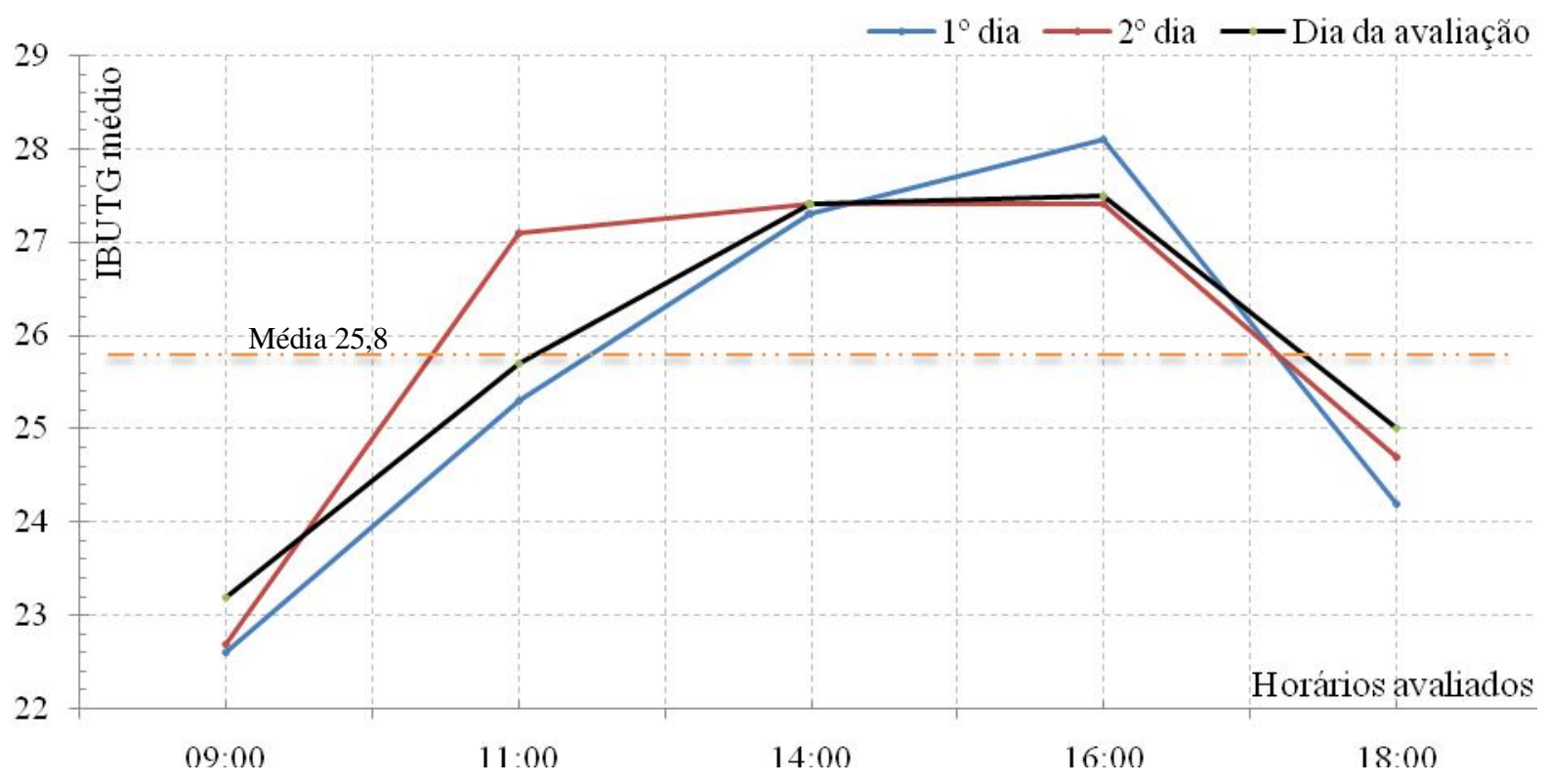

Gráfico 1: Variação do IBUTG médio ao longo da jornada de trabalho, nos horários préestabelecidos para o monitoramento do volume de madeira cortada (st).

Fonte: Leal e Carvalho, 2011.

Para o grupo com descanso, a taxa de metabolismo média ponderada para uma hora foi de $355 \mathrm{Kcal} / \mathrm{h}$ (M), e o valor IBUTG médio ponderado para uma hora foi de 24,9. Portanto, como o IBUTG no local de descanso de 22,2, Tabela 1, foi menor que o índice $(24,9)$ máximo permissível encontrado, segundo o metabolismo médio ponderado (Quadro 2, Anexo 3 da NR-15), o ambiente para descanso atendeu o estabelecido para que as equipes ficassem em bom repouso até retornarem a atividade.

O volume de madeira cortada sofreu grande influência sobre os valores de IBUTG encontrados, principalmente nos horários onde foram registrados os maiores picos de temperaturas, 14:00 e 16:00 horas (Tabela 1).

O decréscimo no volume cortado (st), entre os grupos avaliados, não tiveram visualmente muita variação entre si. A partir das 14:00 horas embora todas as equipes, inclusive as equipes que tinham descanso de 15 minutos a cada 45 minutos trabalhados,apresentassem notado desconforto devido ao forte calor que fazia naquele momento, todas elas mantinham um ritmo de trabalho com um certo raciocínio. Porém, em 
termos de acabamento e precisão de corte, nesse quesito, a qualidade técnica caia drasticamente no grupo sem descanso, ou seja, naquele em que o ritmo era o oferecido pela empresa.

Conforme apresenta o Gráfico 2 abaixo, o decréscimo no volume médio de madeira cortada ao final do período de trabalho já era esperado, porém, confrontado as informações de afastamento por acidentes de funcionários da empresa e os reflexos dos mesmos vivenciados em campo, é possível afirmar que nesse intervalo de horário, das 14:00 as 18:00 horas, foi o período em que mais acidentes aconteceram pelo histórico da empresa. O Gráfico 2 apresenta o volume médio (st) cortado nos horários pré-estabelecidos, pelas equipes avaliadas e também a correspondência desses volumes médios (st) em percentagem.

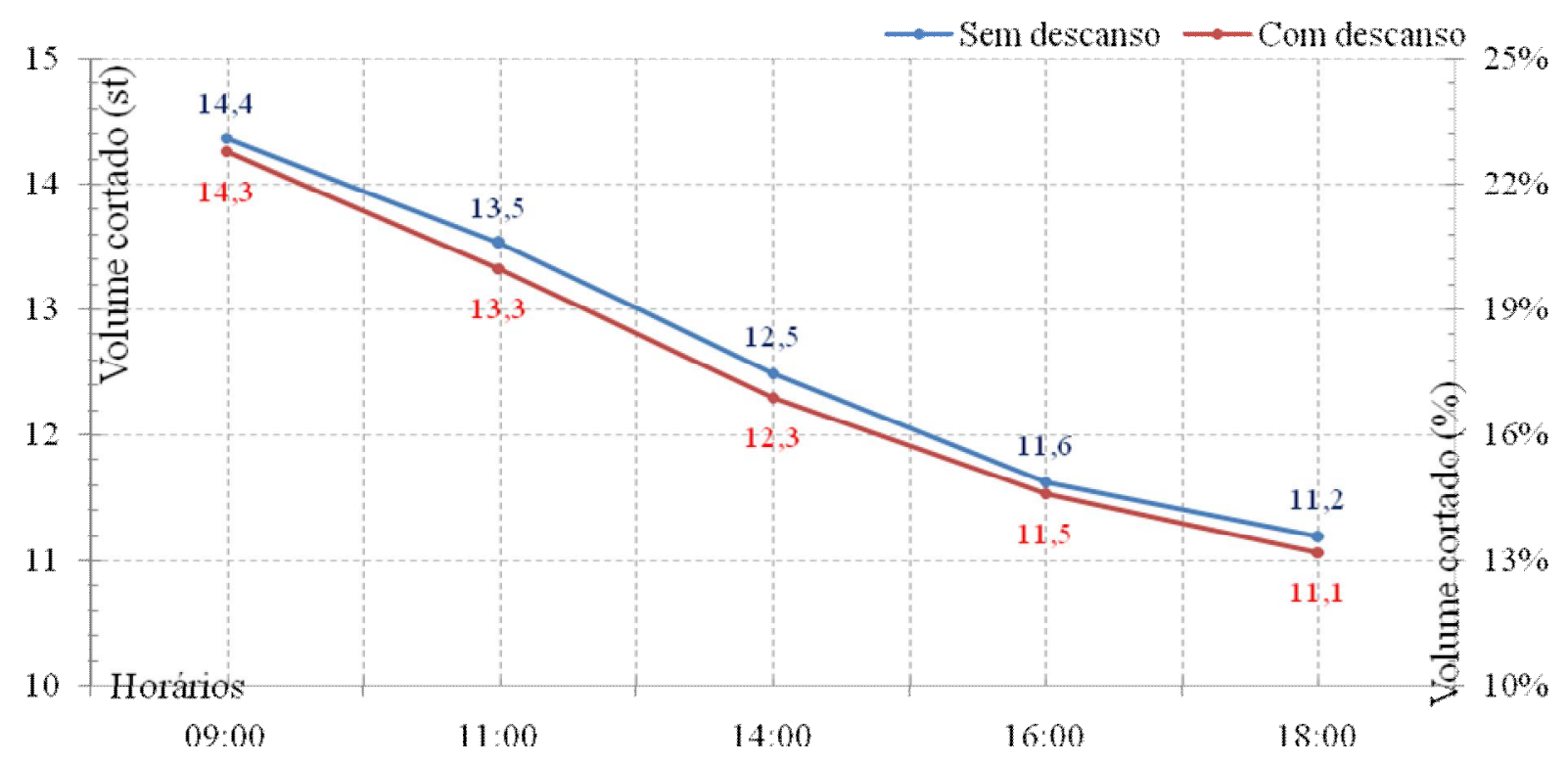

Gráfico 2: Volume médio (st) cortado nos horários pré-estabelecidos, pelas equipes avaliadas no estudo (com e sem descanso), bem como a produção em percentagem de volume cortado.

Fonte: Leal e Carvalho (2011).

Em relação à percentagem de madeira cortada, nos dois regimes de trabalho com e sem descanso, até a hora do almoço, as equipes já haviam cortado um volume de madeira de 27,6 e 27,9 (st), respectivamente. Esses dois montantes corresponderam a 44,1\%de toda produção do dia, em apenas 4 horas de serviço, para ambos os grupos.

O ocorrido se justifica pela condição do ambiente mais favorável do que os grupos encontrariam no decorrer do dia, principalmente pelo aumento e a interferência do calor, conforme apresentado no Gráfico1, onde o IBUTG aumentou significativamente após o horário de almoço, interferência essa também potencializada pelo acúmulo natural do cansaço. 
Também como já era esperado, o rendimento de madeira cortada foi menor no grupo em que o descanso foi oferecido durante o dia, uma vez em que a cada 45 minutos trabalhados, os mesmo descansavam 15 minutos. Fato esse ilustrado nas curvas de produção do Gráfico 2 acima e no Gráfico 3 apresentado na sequencia.

A média de madeira cortada/dia está abaixo daquela pesquisada nas empresas da região, onde um conjunto de trabalhadores (operador de motosserra e ajudante) é capaz de cortar até 100 estéreos (st) de madeira. Porém essa média, encontrada no dia de monitoramento, está dentro de valores aceitáveis na empresa, onde seu melhor conjunto de trabalhadores cortou até a presente data 85 estéreos (st)/dia.

O Gráfico 3 apresenta as médias de volumes cortados durante o dia de avaliação, comparando cada dupla em seu grupo de trabalho, com e sem descanso.Na média em relação à produtividade de madeira cortada, o grupo que trabalhou sem descanso teve uma produtividade, durante o dia, de 63,23 (st). Já o grupo com descanso regular, sistematizado pelo regime de trabalho, teve uma produtividade média de 62,50 (st).

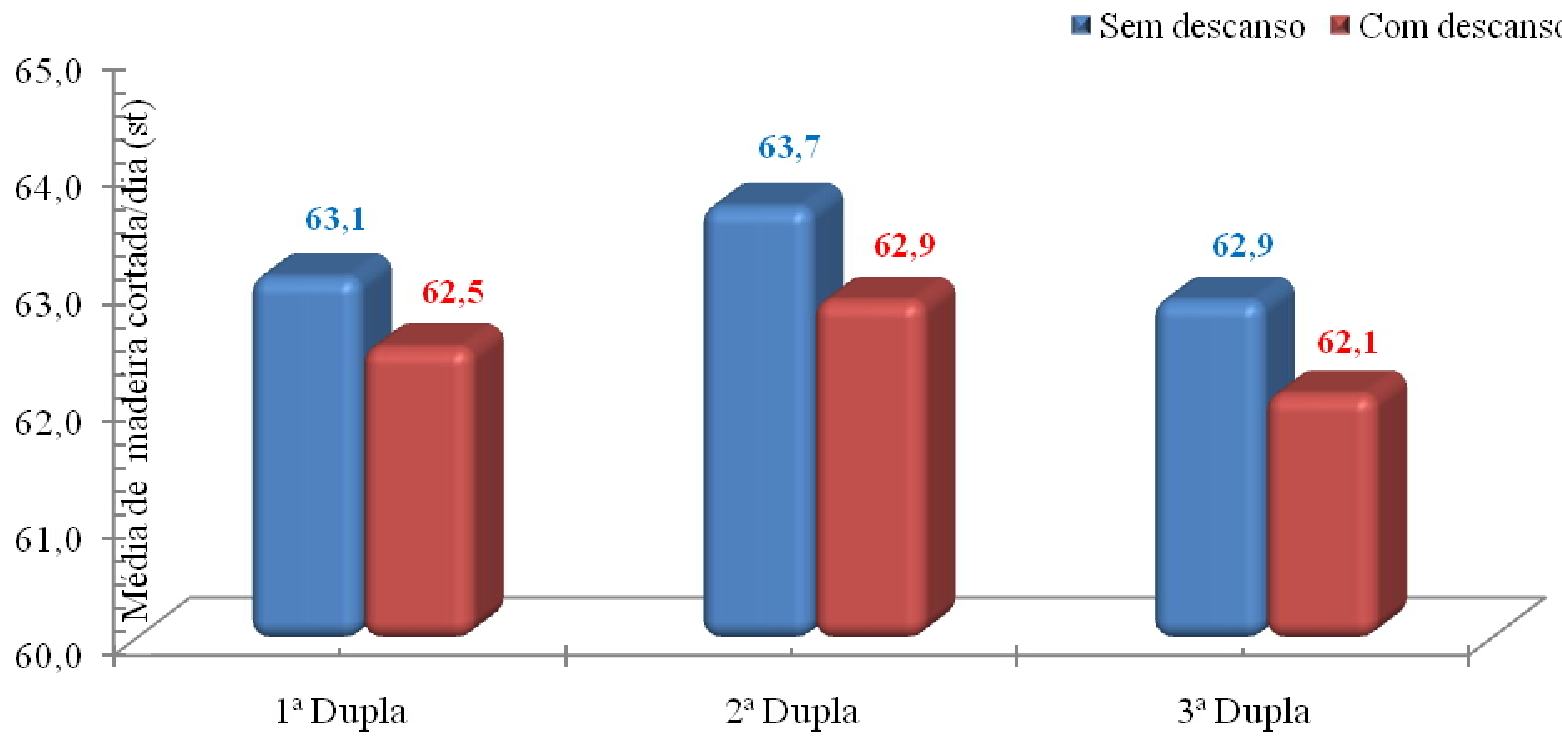

Gráfico 3: Médias de volumes cortados sob os dois regimes de trabalho, com e sem descanso, para cada dupla avaliada em seu regime.

Fonte: Leal e Carvalho (2011).

É notório que o rendimento da equipe que trabalhou sem descanso durante o dia foi, insignificantemente, maior. Porém a uniformidade do entalhe direcional, a precisão do corte de abate, o controle da atividade e o sincronismo entre os componentes (operador e ajudante), em todas as árvores, a qualidade foi muito superior no grupo com descanso. 
Isso terá reflexos importantíssimos na organização do material suprimido em campo, uma vez que o carregamento e o transporte de madeira serão as atividades subsequentes, bem como por serem atividades onerosas e demandar bastante organização do material lenhoso cortado em campo, haverá, com certeza, diferença de rendimento entre as áreas exploradas pelas equipes com e sem descanso.

Outro fato que chamou a atenção foi à uniformidade no decréscimo do volume cortado entre os grupos avaliados. Enquanto o grupo com descanso apresentou grande homogeneidade no decréscimo de volume cortado, entre o maior e o menor volume cortado, com amplitude de 3,30 st, 3,20 st e 3,10 st, respectivamente $1^{\mathrm{a}}, 2^{\mathrm{a}}$ e $3^{\mathrm{a}}$ equipe, o grupo sem descanso variou bastante apresentando maiores amplitudes sendo de 3,90 st, 3,50 st e 3,40 st, respectivamente $1^{\mathrm{a}}, 2^{\mathrm{a}}$ e $3^{\mathrm{a}}$ equipe. $\mathrm{O}$ maior volume cortado em todas as equipes foi entre as 7:00 e as 9:00 $\mathrm{h}$, e o menor foi entre as 16:00 e 18:00 h. O Gráfico 4 apresenta as amplitudes entre o maior e o menor volume de madeira cortada (st) entre as equipes avaliadas sob os dois regimes de trabalho, com e sem descanso.

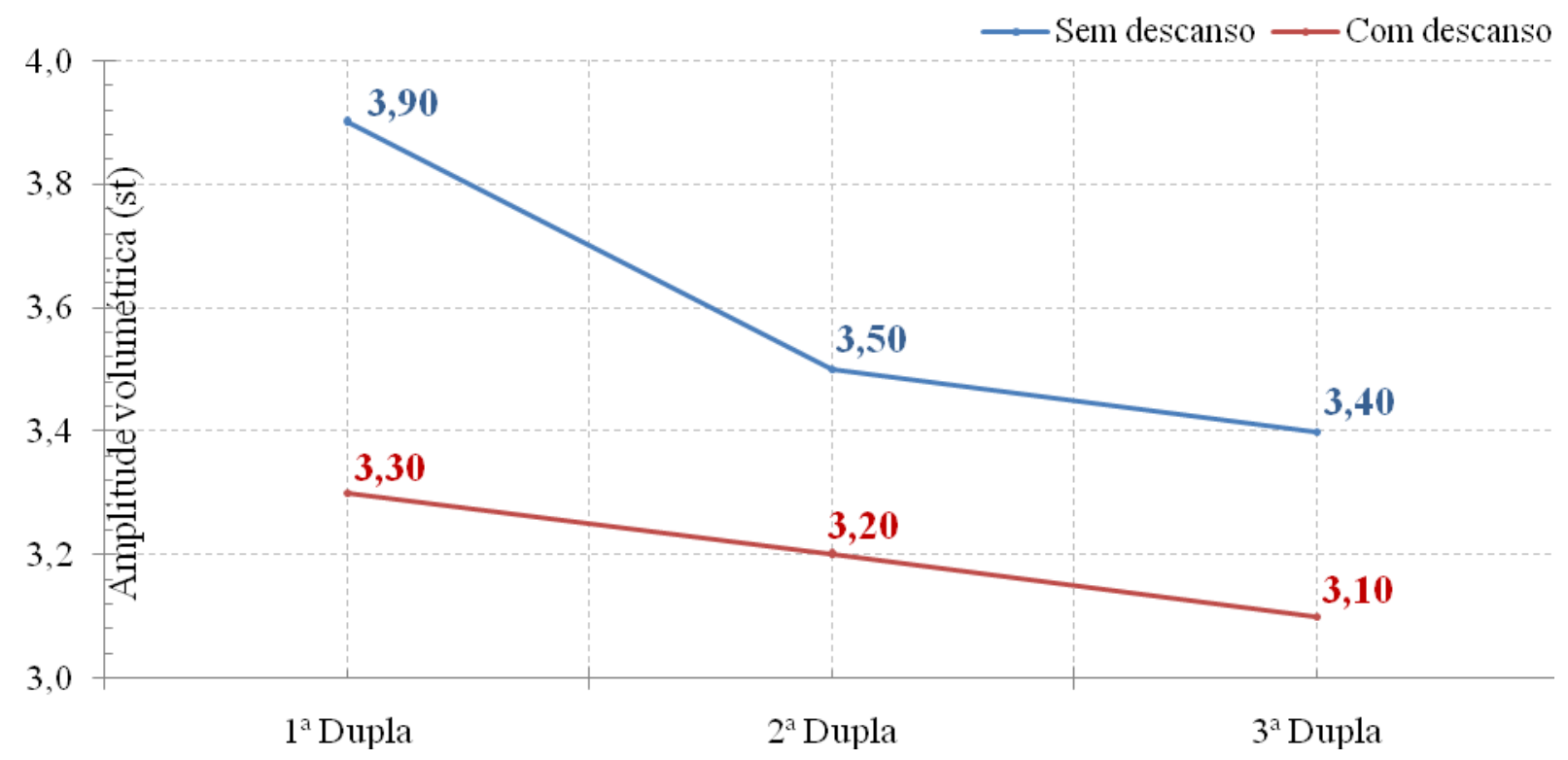

Gráfico 4: Amplitude entre o maior e o menor volume de madeira cortada (st), entre as equipes avaliadas

Fonte: Leal e Carvalho (2011).

Essas amplitudes encontradas sobre a diferença entre o maior e o menor volume de madeira cortada, entre as duplas no grupo sem descanso, refletem com grande fidelidade o sistema de trabalho oferecido pela empresa,em que o funcionário ganhando por produtividade, a qualidade, a saúde e a segurança ficam em terceiro plano.Ou seja, o zelo durante a execução 
da atividade é inexistente,sem nenhuma uniformização de trabalho e ao mesmo tempo preocupante devido terem que produzir muito para receber bem, tornando a atividade cadenciada e de raciocínio em uma atividade mecânica com muitos riscos.

Com a análise de variância feita e apresentada na Tabela 2, a seguir, foi possível constatar que não houve diferença significativa, ao nível de $99 \%$ de probabilidade, entre a variável analisada ( volumes cortados ) para os grupos com e sem descanso. Porém houve diferença significativa a 99\% e a 95\% de probabilidade para os Horários avaliados.

Tal fato seja justificado pelo decréscimo no volume médio apresentado no Gráfico 2, bem como no cansaço visível e vivenciado entre as equipes avaliadas (no grupo com descanso um pouco menos), devido ao esgotamento físico e acumulativo que a atividade de exploração florestal naturalmente oferece.

A Tabela 2 apresenta o resultado da análise de variância realizada entre os tratamentos (regime de trabalho com e sem descanso), horários (9:00, 11:00, 14:00, 16:00 e 18:00) e a interação entre os regimes de trabalho e os horários (Tratamentos x Horários).

Tabela 2: ANOVA realizada para os regimes de trabalho, horários de mensuração de material lenhoso, bem como para a interação entre regimes de trabalho e horários.

\begin{tabular}{|c|c|c|c|c|c|}
\hline Fontes de variação & $\mathrm{GL}^{1}$ & $\mathrm{SQ}^{2}$ & $\mathrm{QM}^{3}$ & Fc & $\mathrm{Pr}>\mathrm{Fc}$ \\
\hline Tratamentos(com e sem descanso) & 1 & 0,16133 & 0,16133 & 3,903 & 0,0622 \\
\hline Horários (9:00, 11:00, 14:00, 16:00 e 18:00) & 4 & 41,17533 & 10,29383 & 249,044 & 0,0000 \\
\hline Tratamentosx Horários & 4 & 0,01533 & 0,00383 & 0,093 & 0,9836 \\
\hline Resíduo & 20 & 0,82667 & 0,04133 & & \\
\hline Total corrigido & 29 & 42,1787 & & & \\
\hline
\end{tabular}

Mesmo não sendo significativa a diferença no volume de madeira cortada entre os grupos avaliados, com e sem descanso, foi realizado um teste de média para os regimes adotados. A Tabela 3 apresenta as médias em volume de madeira cortada (st) para os dois regimes de trabalho. As médias seguidas das mesmas letras não diferem significativamente entre si, pelo Teste de Tukey $(\mathrm{P}<0,01)$.

Tabela 3: Teste de média (Tukey) para os regimes de trabalhos, com e sem descanso.

\begin{tabular}{lcc}
\hline Tratamentos (regime de trabalho) & Médias (st) & Resultado do teste \\
\hline Com descanso & 12,50 & a \\
Sem descanso & 12,64 & a \\
\hline
\end{tabular}

Fonte: Leal e Carvalho (2011). 
Fica evidenciado que o regime de trabalho deve ser revisto pela empresa, uma vez que a qualidade de corte e a uniformidade do material lenhoso cortado está prejudicando o produto final. E que o sistema de gratificação por produtividade pode ocasionar acidentes irreparáveis aos funcionários gerando ônus de grande repercussão á empresa.

Já para os horários avaliados nos estudos, conforme Tabela 2, houve diferenças significativas nos volumes de madeira cortada. O fato se justifica devido ao cansaço demonstrado à medida que a atividade de exploração avança no decorrer do dia, corroborando mais uma vez com o Gráfico 2 apresentado.

A Tabela 4 apresenta o teste de média realizado para os horários pré-estabelecidos de medição de volume de madeira cortada. As médias seguidas das mesmas letras não diferem significativamente entre si, pelo Teste de Tukey $(\mathrm{P}<0,01)$.

Tabela 4: Teste de média (Tukey) realizado para os horários de medição de madeira cortada.

\begin{tabular}{|c|c|c|}
\hline Horários avaliados & Médias (st) & Resultado do teste \\
\hline 09:00 & 14,32 & $\mathrm{a}$ \\
\hline $11: 00$ & 13,43 & $\mathrm{~b}$ \\
\hline $14: 00$ & 12,40 & c \\
\hline $16: 00$ & 11,58 & $\mathrm{~d}$ \\
\hline $18: 00$ & 11,13 & $\mathrm{e}$ \\
\hline
\end{tabular}

Fonte: Leal e Carvalho, 2011.

O operador de motosserra foi o funcionário que apresentou maiores reclamações sobre cansaço. Ele é o único que pode operar o equipamento de corte (motosserra) e ainda sustenta um conjunto próprio de equipamentos de proteção individual que lhe garante integridade física em casos de acidentes.

O decréscimo na produção durante o dia está intimamente ligado ao fato que não há revezamento entre operadores e nem operadores reservas habilitados para desempenhar tal função.

Com a ANOVA feita para o desdobramento do fator Tratamento (com e sem descanso) dentro de cada nível de Horário (9:00, 11:00, 14:00, 16:00 e 18:00), Tabela 5, foi possível admitir que não houve diferença significativa, ao nível de $1 \%$ de probabilidade, nos volumes de madeira cortada, entre os regimes de trabalho nos horários pré-estabelecidos para medição dos volumes de madeira. Evidenciando aqui a igualdade na produtividade entre as equipes avaliadas no presente trabalho. A Tabela 5 mostra o resultado da ANOVA para a análise acima citada e os valores não significativos para F. 
Tabela 5: ANOVA para o desdobramento do fator Tratamento (com e sem descanso) em cada nível de Horário.

\begin{tabular}{lccccc}
\hline Fontes de variação & $\mathrm{GL}^{1}$ & $\mathrm{SQ}^{2}$ & $\mathrm{QM}^{3}$ & $\mathrm{Fc}$ & $\mathrm{Pr}>\mathrm{Fc}$ \\
\hline Tratamento (com e sem descanso) 09:00 h & 1 & 0,01500 & 0,01500 & 0,363 & 0,5537 \\
Tratamento (com e sem descanso) 11:00 h & 1 & 0,06000 & 0,06000 & 1,452 & 0,2423 \\
Tratamento (com e sem descanso) 14:00 h & 1 & 0,06000 & 0,06000 & 1,452 & 0,2423 \\
Tratamento (com e sem descanso) 16:00 h & 1 & 0,01500 & 0,01500 & 0,363 & 0,5537 \\
Tratamento (com e sem descanso) 18:00 h & 1 & 0,02666 & 0,02666 & 0,645 & 0,4313 \\
Resíduo & 20 & 0,82667 & 0,04133 & & \\
\hline
\end{tabular}

${ }^{1}$ Grau de liberdade ${ }^{2}$ Soma de quadrados ${ }^{3}$ Quadro médio

Fonte: Leal e Carvalho, 2011.

Com a ANOVA feita para o desdobramento do fator Horário (9:00, 11:00, 14:00, 16:00 e 18:00) dentro de cada nível de Tratamento (com e sem descanso), Tabela 6, foi possível constatar diferença significativa, ao nível de $1 \%$ de probabilidade, entre os volumes cortados em alguns horários pré-estabelecidos de mensuração do volume. Tal fato foi observado após o teste de média realizado, principalmente para aqueles horários próximos ao fim do expediente de trabalho.

Para os dois grupos de trabalho, com e sem descanso, foi constatado o mesmo cenário, onde há uma nítida queda de rendimento no volume de madeira cortada, corroborando mais uma vez com as declarações dos funcionários sobre o período histórico de maior acontecimento de acidentes na empresa.

Fato também já discutido com a apresentação do Gráfico 2, anteriormente mostrado, e com grandes preocupações, pois além do horário aproximado com a saída do trabalho, há uma intensa carga acumulativa de cansaço, bem como uma diminuição acentuada dos reflexos naturais sobre o controle dos equipamentos utilizados na exploração, em especial o motosserra. A Tabela 6 a seguir mostra o resultado da ANOVA para a análise anteriormente citada e os valores significativos para $\mathrm{F}$.

Tabela 6: ANOVA para o desdobramento do fator Horário (9:00, 11:00, 14:00, 16:00 e 18:00) em cada nível de Tratamento.

\begin{tabular}{lccccc}
\hline Fontes de variação & $\mathrm{GL}^{1}$ & $\mathrm{SQ}^{2}$ & $\mathrm{QM}^{3}$ & $\mathrm{Fc}$ & $\mathrm{Pr}>\mathrm{Fc}$ \\
\hline Horários (com descanso) & 4 & 20,53330 & 5,13333 & 124,194 & 0,0000 \\
Horários (sem descanso) & 4 & 20,65730 & 5,16433 & 124,944 & 0,0000 \\
Resíduo & 20 & 0,82667 & 0,04133 & & \\
\hline
\end{tabular}

${ }^{1}$ Grau de Liberdade ${ }^{2}$ Soma de quadrados ${ }^{3}$ Quadrado médio.

Fonte: Leal e Carvalho (2011).

Deste modo, com os testes de média realizados para os dois regimes de trabalho, com e sem descanso, foi notório a correlação entre os regimes de trabalho nos horários de 16:00 e 
18:00 horas, conforme Tabelas 7 e 8 . Tal fato pode ser explicado pelos funcionários não conseguirem manter a produtividade,pelo esgotamento físico e perdas de reflexos já anteriormente citados.Apesar do decréscimo no volume, o grupo com descanso apresentou melhores condições de qualidade de corte e uniformidade no material lenhoso suprimido.

As Tabelas 7 e 8 apresentam os resultados do teste de média (Tukey) para o grupo com descanso e sem descanso, respectivamente. As médias seguidas pelas mesmas letras não diferem significativamente entre si, pelo Teste de Tukey $(\mathrm{P}<0,01)$.

Tabela 7: Teste de média com o volume de madeira cortado para o regime de trabalho com descanso.

\begin{tabular}{cccccc}
\hline Horários avaliados & Médias (st) & \multicolumn{2}{c}{ Resultado do teste } \\
\hline $09: 00$ & 14,27 & a & & \\
$11: 00$ & 13,33 & & $\mathrm{~b}$ & & \\
$14: 00$ & 12,30 & & & $\mathrm{c}$ & \\
$16: 00$ & 11,53 & & & & $\mathrm{~d}$ \\
$18: 00$ & 11,06 & & & & $\mathrm{~d}$ \\
\hline
\end{tabular}

Fonte: Leal e Carvalho (2011).

Tabela 8: Teste de média com o volume de madeira cortado para o regime de trabalho sem descanso.

\begin{tabular}{cccccc}
\hline Horários avaliados & Médias $(\mathrm{st})$ & \multicolumn{2}{c}{ Resultado do teste } \\
\hline $09: 00$ & 14,37 & $\mathrm{a}$ & & & \\
$11: 00$ & 13,53 & & $\mathrm{~b}$ & & \\
$14: 00$ & 12,50 & & & $\mathrm{c}$ & \\
$16: 00$ & 11,63 & & & & $\mathrm{~d}$ \\
$18: 00$ & 11,20 & & & & $\mathrm{~d}$ \\
\hline
\end{tabular}

Fonte: Leal e Carvalho (2011).

Em análise geral, após observações realizadas e vivenciadas em campo, as condições de segurança do trabalho durante a atividade na exploração florestal, no local de estudo, atende o mínimo necessário sobre treinamentos para operadores de motosserra, equipamentos de proteção individual, trabalhos a céu aberto, dentre outros.

É claro que algumas melhorias devem ser feitas o quanto antes possível, porém isso só será possível com a contratação de um profissional de segurança do trabalho e com a anuência da empresa terceirizada aqui avaliada. 
Uma delas seria a adoção imediata da NR-31 onde determina ao empregador fornecer instruções compreensíveis em matéria de segurança e saúde, bem como toda orientação necessária ao trabalho seguro.

Todos os motosserras estavam equipados com sistema de proteção para seu operador, como trava do acelerador, proteção da mão e pino pega-corrente, de acordo com a NR-12 e NR-31, fato esse muito importante para a segurança do trabalhador.

\section{CONSIDERAÇÕES FINAIS}

Fica evidenciado que independentemente do IBUTG calculado, o descanso poderia ser oferecido pela empresa, em qualquer época do ano, sem nenhum ônus aos funcionários e a ela também, uma vez que estatisticamente não houve diferença significativa entre os regimes de trabalho adotados.

As consequências da adoção do descanso terão tendências positivas, uma vez que em campo a qualidade do serviço, do grupo que trabalhou com descanso, foi muito superior em detrimento ao outro regime de trabalho.

O sistema de trabalho por produtividade pode trazer consequências negativas para a empresa e principalmente para os funcionários. Esse regime desperta um desejo de produtividade incompatível com a saúde e segurança do trabalhador. Fato presenciado em campo, onde houve resistências enormes quando da proposição de mudança no regime de trabalho, apenas de um dia para a elaboração deste estudo.

Outra prática que pode ser adotada é o fornecimento de um alimento rico em glicose, por exemplo, rapadura, paçoca, etc., para os funcionários (com exceção aos diabéticos), haja vista que os mesmos não recebem outra alimentação a não ser o almoço. Alguns fatos isolados como tonteiras, desequilíbrios, dentre outros, foram percebidos em campo, devido ao grande esforço físico que os funcionários naturalmente são submetidos.

Em geral pode se notar nas equipes uma grande falta de atenção e de alguns cuidados básicos nos procedimentos corretos já amplamente conhecidos no meio florestal. Fato esse também encontrado por Pescador e Oliveira (2009). Ressaltando também que, infelizmente, a falta de atenção não pode ser adquirida em treinamentos e por isso ainda poderemos ter alguns acidentes lamentáveis e indesejáveis no setor.

A falta de um profissional de segurança do trabalho para realização de treinamentos e orientações para o desenvolvimento da atividade está contribuindo negativamente para o cenário. Este profissional reúne todas as características necessárias para se fazer um bom 
planejamento na saúde e na segurança do trabalhador, bem como em ações estratégicas que, mesmo existindo risco na atividade, possam ser mitigados com atuações seguras e delineadas.

A exploração florestal semimecanizada é uma atividade difícil, perigosa e ainda muito rebatida, mas se planejada de forma eficiente pode trazer grandes benefícios às empresas e aos seus funcionários.

\section{REFERÊNCIAS}

BRACELPA - ASSOCIAÇÃO BRASILEIRA DE CELULOSE E PAPEL. Relatório estatístico 2007/2008. São Paulo, 2008.

FERREIRA, D. F. Sistema de análises de variância para dados balanceados. Lavras: UFLA, 2000. (SISVAR 5.3. pacote computacional).

LEITE, Â. M. P.; SOUZA, A. P.; MACHADO, C. C. Terceirização. In: MACHADO, C. C. (coord.). Colheita florestal. Viçosa: UFV, 2002, p. 423-444.

MACHADO, C. C.(ed.) Colheita Florestal. 2.ed. atual e ampl. Viçosa: UFV, 2008.

NOVAIS, L. F. Análise da colheita florestal mecanizada em povoamentos de Eucalyptus spp.na região de Coronel Fabriciano - MG. 33 f. 2006. Monografia, Universidade Federal Rural do Rio de Janeiro. Seropédica.

PESCADOR, C.M.M.; OLIVEIRA, A. J. de. Segurança do trabalho na colheita florestal: um estudo de caso. 2009. Trabalho de conclusão de curso (Pós-graduação em Engenharia de Segurança do Trabalho) - Departamento de Engenharia Civil, Setor de Ciências Agrárias e Tecnológicas, Universidade Estadual de Ponta Grossa.

SOUZA, M. A; PIRES, C. B. Colheita florestal: mensuração e análise dos custos incorridos na atividade mecanizada de extração. Custos e agronegócio online. v. 5, n. 2, maio/ago. 2009. 
